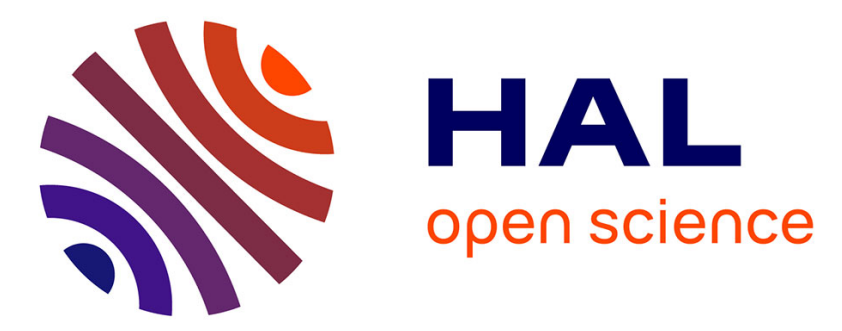

\title{
A Predictive power control of Doubly Fed Induction Generator for Wave Energy Converter in Irregular Waves
}

\author{
Mouna Lagoun, Atallah Benalia, Mohamed Benbouzid
}

\section{To cite this version:}

Mouna Lagoun, Atallah Benalia, Mohamed Benbouzid. A Predictive power control of Doubly Fed Induction Generator for Wave Energy Converter in Irregular Waves. IEEE ICGE 2014, Mar 2014, Sfax, Tunisia. pp.26-31. hal-01023509

\section{HAL Id: hal-01023509 https://hal.science/hal-01023509}

Submitted on 13 Jul 2014

HAL is a multi-disciplinary open access archive for the deposit and dissemination of scientific research documents, whether they are published or not. The documents may come from teaching and research institutions in France or abroad, or from public or private research centers.
L'archive ouverte pluridisciplinaire HAL, est destinée au dépôt et à la diffusion de documents scientifiques de niveau recherche, publiés ou non, émanant des établissements d'enseignement et de recherche français ou étrangers, des laboratoires publics ou privés. 


\section{A Predictive power control of Doubly Fed Induction Generator for Wave Energy Converter in Irregular Waves}

\author{
M.S. Lagoun ${ }^{1}$, A.Benalia ${ }^{1}$ \\ ${ }^{1}$ Laboratoire d'Analyse et de Commande des \\ Systèmes d'Energie et Réseaux Electriques \\ LACoSERE, Laghouat, Algeria \\ mouna.lagoun@gmail.com
}

\author{
M.E.H Benbouzid ${ }^{2}$ \\ ${ }^{2}$ Laboratoire Brestois de Mécanique et des \\ Systèmes, EA 4325 LBMS \\ Brest, France \\ Mohamed.Benbouzid@univ-brest.fr
}

\begin{abstract}
In last decades, renewable energy resources are considered as an alternative energy resource to the World's excessive energy demand. An extremely abundant and promising source of energy exists in oceans. Currently, there are several wave energy converters to harness this energy. Some of them, as in tidal applications, use the Doubly-fed induction generator. This paper deals then with a predictive power control of this generator based Wave Energy Converter under irregular wave climate which is modeled as time series elevation from using Bretschneider spectra. In the proposed control approach, the predicted output power was calculated using a linearized statespace model. The DFIG-based WEC power tracking performances further illustrates the dynamic features of the proposed predictive power control approach.
\end{abstract}

Keywords - Wave energy converter (WEC), irregular wave, doubly-fed induction generator (DFIG), predictive power control,

\section{INTRODUCTION}

The world energy demand is increasing at an alarming rate, and producing electricity from alternative or renewable energy sources is becoming a necessity. Among renewable energy harvesting technologies which are still being investigated through various industrial and academic group, wave energy harvesting technology has already shown to be practical, since oceans cover almost $70 \%$ of the earth's surface [1-2].

Numerous techniques for extracting energy from the sea have been suggested, most of which can be included in one of the following categories: wave energy, marine and tidal current energy, ocean thermal energy, energy from salinity gradients (osmosis), and cultivation of marine biomass. The global theoretical energy from waves corresponds to 1500 TWh/year, which is about 100 times the total hydroelectricity generation of the whole planet [3].

To harness the power energy in waves present a different set of technical challenges and a wide variety of designs have been suggested. There are many devices which are generally categorized by the installation location and the power take-off. Therefore, most devices can be characterized as belonging to six types. These are attenuator, point absorber, oscillating wave surge converter, oscillating water column, overtopping device, and submerged pressure differential [4-5].

In all WECs, a mechanical interface is used to convert the slow rotational speed or reciprocating motion into high speed rotational motion for connection to a conventional rotating electrical generator as a DFIG (Fig. 1).

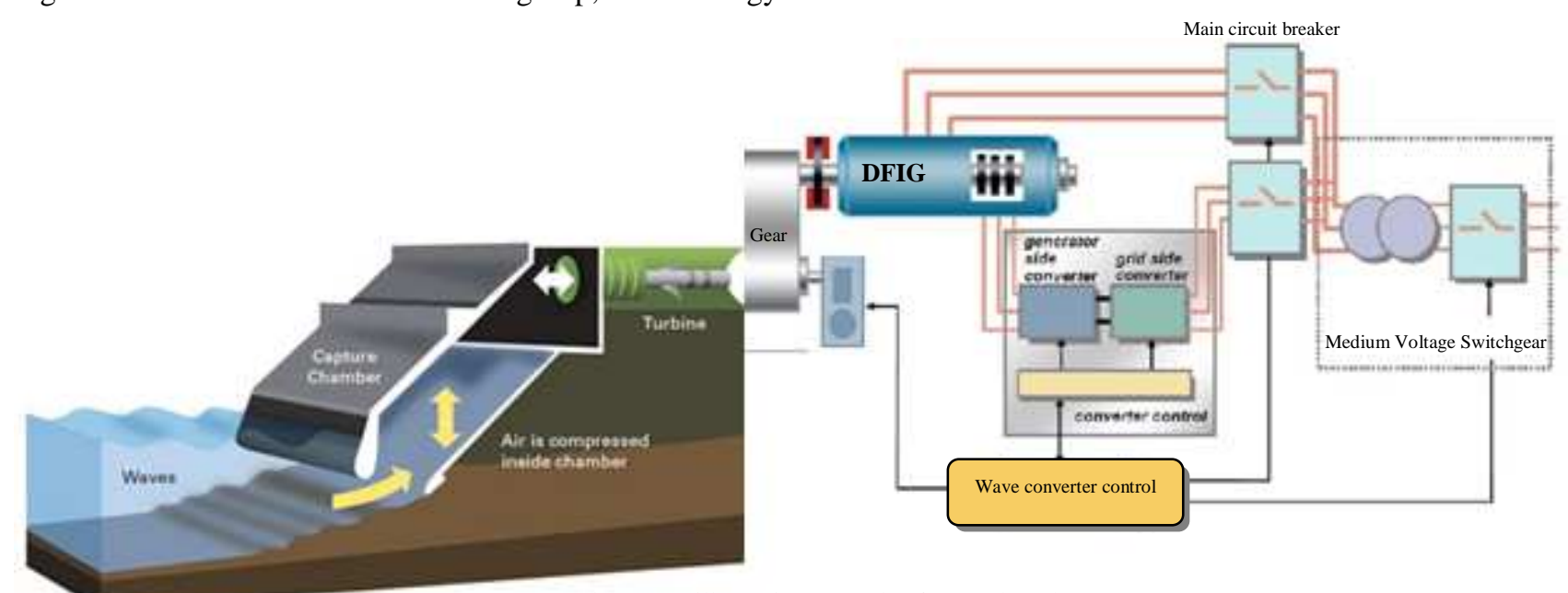

Fig.1. An illustrative example of DFIG-based WEC. 
The control of the active and reactive power is achieved with a rotor current controller. Several investigations have been carried-out for that reason like the classical PI controllers. However, the problem in the use of PI controllers is gains tuning and DFIG terms cross-coupling in the whole operating range. There are many interesting methods to solve these problems have been presented in [6-15]. In the last reference, we have we applied a Model-Based Predictive Control (MBPC) strategy for DFIG-based wave energy converters with the main objective to solve the above-cited control problems. In this paper, we applied the same algorithm in case that our converter is under irregular wave.

\section{IRREGULAR WAVE MODEL}

\section{A. Nomenclature}

$\begin{array}{ll}\rho & \text { Water density } \\ g & \text { Gravity } \\ T_{s} & \text { Peak period of wave } \\ \omega_{0} & \text { Peak Frequency of wave } \\ H_{s} & \text { Significant height of the wave } \\ \eta & \text { Wave surface elevation } \\ \varphi & \text { Wave phase }\end{array}$

Wave motion and wave energy absorption are composed of time-varying oscillatory phenomena. For the study of regular waves, it is necessary to take into account wave climate spectrum that indicates the amount of wave energy at different wave frequencies. Then, the regular wave is modeled and is typically described in terms of power per meter of wave front (wave crest length) [5],[16-18].

$$
P_{w f}=\rho g^{2} H_{s}^{2} T_{s} / 32 \pi
$$

. There are different mathematical models that are used for defining such specters[18]. The analytical form is given by the following equation:

$$
S(\omega)=\frac{5}{16} H_{s}{ }^{2} \frac{\omega_{0}}{\omega} e^{-\frac{5}{4}\left(\frac{\omega_{0}}{\omega}\right)}
$$

The spectrum used for the simulations is illustrate in (Fig. 2.) where $T_{s}=11 s$ and $H_{s}=7 \mathrm{~s}$.

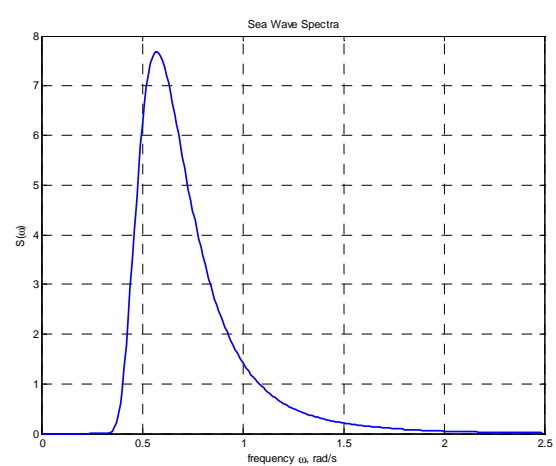

Fig. 2. Bretschneider spectrum with $T_{S}=11 \mathrm{~s}$ and $H_{S}=7 \mathrm{~s}$.
Once the spectrum has been defined, the wave surface elevation of the $\mathrm{i}$ component wave can be found and created by randomly phase shifting and summing several sinusoids of different heights and periods by this equation:

$$
\eta(x, t)=\sum_{i}^{n} H_{i} \cos \left(\omega_{i} t+\varphi_{i}\right)
$$

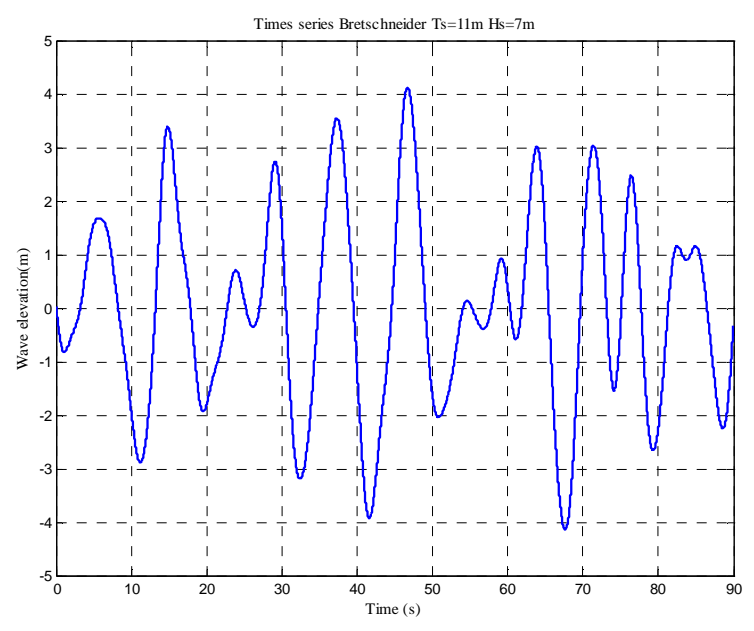

Fig. 3. Wave elevation for $T_{s}=11 s$ and $H_{s}=7 s$.

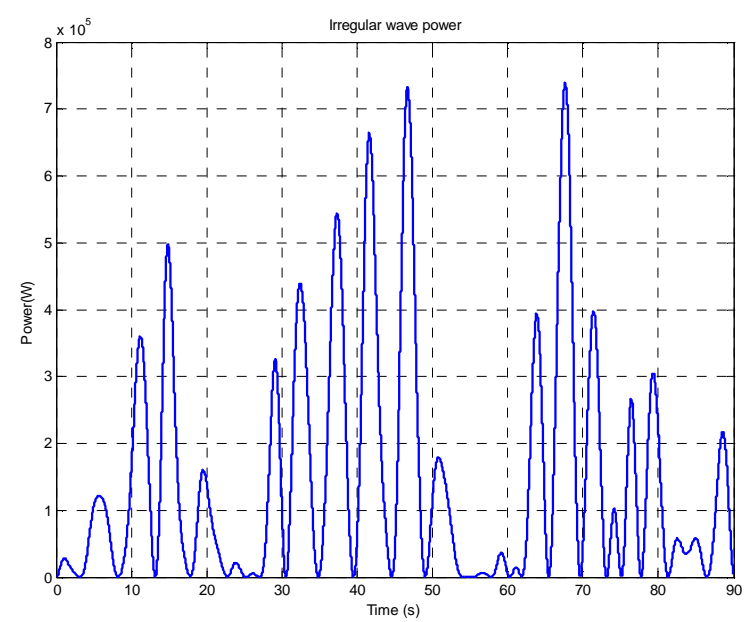

Fig. 4. Power extracted from irregular wave for $T_{s}=11 \mathrm{~s}$ and $H_{s}=7 \mathrm{~s}$.

\section{DFIG MODEL AND ROTOR CURRENT CONTROL}

A. Nomenclature

$\begin{array}{ll}s,(r) & \text { Stator (rotor) index; } \\ d, q & \text { Synchronous reference frame index; } \\ V(I) & \text { Voltage (Current); } \\ \Psi & \text { Flux; } \\ R & \text { Resistance; } \\ L & \text { Inductance; } \\ L m & \text { Magnetizing inductance; } \\ \sigma & \text { Leakage coefficient, } \sigma=1-L_{m}^{2} / L_{s} L_{r} ; \\ \omega_{s}\left(\omega_{m e c}\right) & \text { Synchronous speed (rotor speed) } \\ P & \left(\omega_{s l}=\omega_{s l}-P \omega_{m e c}\right) ; \\ & \text { Pole-pair number; }\end{array}$


For decoupled control, dynamic model is required. The DFIG model in the synchronous reference frame is given by [19][20]:

$$
\begin{aligned}
& \vec{V}_{s d q}=R_{s} \vec{I}_{s d q}+\frac{d \overrightarrow{\psi_{s}}}{d t}+j \omega_{s} \vec{\psi}_{s d q} \\
& \vec{V}_{r d q}=R_{r} \vec{I}_{r d q}+\frac{d \overrightarrow{\psi_{r}}}{d t}+j\left(\omega_{s}-P \omega_{m e c}\right) \vec{\psi}_{r d q}
\end{aligned}
$$

where the relationship between fluxes and currents is:

$$
\begin{aligned}
& \vec{\psi}_{s d q}=L_{s} \vec{I}_{s d q}+L_{m} \vec{I}_{r d q} \\
& \vec{\psi}_{r d q}=L_{m} \vec{I}_{s d q}+L_{r} \vec{I}_{r d q}
\end{aligned}
$$

And generator active and reactive power are:

$$
\begin{aligned}
& P=\frac{3}{2}\left(V_{d s} I_{d s}+V_{q s} I_{q s}\right) \\
& Q=\frac{3}{2}\left(V_{d s} I_{d s}-V_{q s} I_{q s}\right)
\end{aligned}
$$

The DFIG power control aims independent stator active and reactive power control by means a rotor current regulation. For this principle, and are represented as functions of each individual rotor current. We use stator flux oriented control that decouples the $d q$ axis, which means $\psi_{\mathrm{ds}}=\psi_{\mathrm{s}}$ :

$$
\begin{aligned}
& I_{d s}=\frac{\psi_{s}}{L_{s}}-\frac{L_{m}}{L_{s}} I_{d r} \\
& I_{q s}=-\frac{L_{m}}{L_{s}} I_{d r}
\end{aligned}
$$

By using stator flux oriented the stator voltage becomes $V_{\mathrm{ds}}=0$ and "(5)" can be writing:

$$
\begin{aligned}
& P=-\frac{3}{2} V s \frac{L_{m}}{L_{s}} I_{r q} \\
& Q=\frac{3}{2}\left(\frac{\psi_{s}}{L_{s}}-\frac{L_{m}}{L_{s}} I_{r q}\right)
\end{aligned}
$$

The rotor currents control, using "(7)", allows the DFIG power control. The rotor voltage "(3)", in the synchronous referential frame using the stator flux position, and by using "(6)", becomes:

$$
\begin{aligned}
\vec{V}_{r d q}= & \left(R_{r}+j \sigma L_{r} \omega_{s l}\right) \vec{I}_{r d q}+\sigma L_{r} \frac{d \vec{I}_{r d q}}{d t} \\
& +j \frac{L_{m}}{L_{s}} \omega_{s l} \psi_{s}
\end{aligned}
$$

The last equation can be writing in space state form:

$$
\left\{\begin{array}{l}
\dot{x}=A x+B u+G w \\
y=C u
\end{array}\right.
$$

$$
\begin{aligned}
{\left[\begin{array}{c}
\dot{P} \\
\dot{Q}
\end{array}\right] } & =\left[\begin{array}{cc}
\frac{-R_{r}}{\sigma L_{r}} & -g \omega_{s} \\
g \omega_{s} & \frac{-R_{r}}{\sigma L_{r}}
\end{array}\right]\left[\begin{array}{l}
P \\
Q
\end{array}\right]+\left[\begin{array}{cc}
-\frac{3}{2} \frac{V_{s} M}{L_{s} L_{r} \sigma} & 0 \\
0 & -\frac{3}{2} \frac{V_{s} M}{L_{s} L_{r} \sigma}
\end{array}\right]\left[\begin{array}{c}
V_{q r} \\
V_{d r}
\end{array}\right] \\
& +\left[\begin{array}{ll}
1 & 0 \\
0 & 1
\end{array}\right]\left[\begin{array}{c}
\frac{3}{2} \frac{g}{L_{s}}\left(1+\frac{M^{2}}{L_{s} L_{r} \sigma}\right) V_{s}^{2} \\
\frac{3}{2} \frac{R_{r}}{\sigma L_{s} L_{r} \omega_{s}} V_{s}^{2}
\end{array}\right]
\end{aligned}
$$

\begin{tabular}{|c|c|}
\hline & \\
\hline$N_{p}$ & $=$ Prediction horizon output; \\
\hline$N_{u}$ & = Control horizon; \\
\hline$Y$ & $=$ Predicted output; \\
\hline$U$ & $=$ Input. \\
\hline
\end{tabular}

$\mathrm{C}$ is the identity matrix. For a simple time, $\omega_{\text {mec }}$ is constant [21] and the rotor applied voltage is constant during a control period of the PWM voltage source inverter. This equation can be discretized as:

$$
\left\{\begin{array}{l}
x(k+1)=A_{d} x(k)+B_{d} u(k)+G_{d} w(k) \\
y(k+1)=C_{d} u(k)
\end{array}\right.
$$

Where

$$
\begin{aligned}
& \mathrm{A}_{\mathrm{d}}=\mathrm{e}^{\mathrm{A} T_{e}} \cong \mathrm{I}+\mathrm{A} T_{e} \\
& \mathrm{~B}_{\mathrm{d}}=\int_{0}^{\tau} \mathrm{e}^{\mathrm{A} T_{e}} \mathrm{Bd} \tau \cong \mathrm{B} T_{e} \\
& \mathrm{G}_{\mathrm{d}}=\int_{0}^{\tau} \mathrm{e}^{\mathrm{A} T_{e}} \mathrm{Gd} \tau \cong \mathrm{G} T_{e} \\
& \mathrm{C}_{\mathrm{d}}=\mathrm{C}
\end{aligned}
$$

This linear discrete space state model of DFIG will be used in our scheme algorithm to calculate output power.

\section{MODEL BASED PREDICTIVE CONTROL}

A. Nomenclature

B. $M B P C$

Model-based predictive control involves a class of control techniques that consists of two main elements: the model of the system being controlled and the optimizer that determines the optimal future control actions. The system model is used to predict the future behavior of the system with control law obtained by optimizing a cost-function [14].

The cost-function considers the effort needed to control the deviation between the expected and the real values.

$$
Y=N x(k)+H U+D W_{e}
$$

Where

$$
\begin{aligned}
& Y=\left[\begin{array}{lll}
y(k+1) & y(k+2) & \ldots y\left(k+n_{y}\right)
\end{array}\right]^{T} \\
& U=\left[\begin{array}{lll}
u(k+1) & u(k+2) & \ldots u\left(k+n_{y}\right)
\end{array}\right]^{T}
\end{aligned}
$$




$$
\begin{aligned}
W_{e} & =\left[\begin{array}{llll}
w_{e}(k) & w_{e}(k+1) & w_{e}\left(k+N_{u}-1\right)
\end{array}\right]^{T} \\
N & =\left[\begin{array}{lllll}
C_{D} A_{D} & C_{D} A_{D}^{2} & C_{D} A_{D}^{N_{p}}
\end{array}\right]^{T} \\
H & =\left[\begin{array}{cccc}
C_{D} B_{D} & 0 & 0 & \\
C_{D} A_{D} B_{D} & C_{D} B_{D} & 0 & \\
C_{D} A_{D}^{2} B_{D} & C_{D} A_{D} B_{D} & C_{D} B_{D} & \vdots \\
\vdots & \vdots & \vdots & \vdots \\
C_{D} A_{D}^{N_{p}-1} B_{D} & C_{D} A_{D}^{N_{p}-2} B_{D} & & C_{D} A_{D}^{N_{p}-N_{u}} B_{D}
\end{array}\right]
\end{aligned}
$$

$$
D=\left[\begin{array}{cccc}
C_{D} G_{D} & 0 & 0 & \\
C_{D} A_{D} G_{D} & C_{D} G_{D} & 0 & \\
C_{D} A_{D}^{2} G_{D} & C_{D} A_{D} G_{D} & C_{D} G_{D} & \\
\vdots & \vdots & \vdots & \vdots \\
C_{D} A_{D}^{N N^{-1}} G_{D} & C_{D} A_{D}^{N_{p}-2} G_{D} & & C_{D} A_{D}^{N p^{-N_{u}}} G_{D}
\end{array}\right]
$$

Where $N_{p}$ is the prediction horizon output, $N_{u}$ is the control horizon, $\mathrm{Y}$ is the predicted output. The choice of $N_{p}$ is critical for the performance of control.

The control law is obtained by minimizing the quadratic cost function. The quadratic function is given by:

$$
J=\left(Y_{\text {ref }}-Y\right)^{T} W_{y}\left(Y_{\text {ref }}-Y\right)+U^{T} W_{u} U
$$

If $N_{u}=1$, the maghitude of entries represents an average value that allows the output $\mathrm{s}$ to follow the references. If $N_{u}>1$, the output will be more closely to the reference, but the chosen of big value increase the computational costs. The minimal value of $J$ is obtained by $\partial J / \partial U=0$. For each control cycle, the matrix $N, D$ and $H$ must be updated. The substitution of $Y$ from "(11)" into "(18)", results the derivation of the cost function depends on $U$, which we permit to obtain an analytical solution. Thus this expression is given by:

$$
U=\left(H^{T} W_{y} H+W_{u}\right)^{-1} H^{T} W_{y}\left(Y_{r e f}-N x(k)-D W_{e}\right)
$$

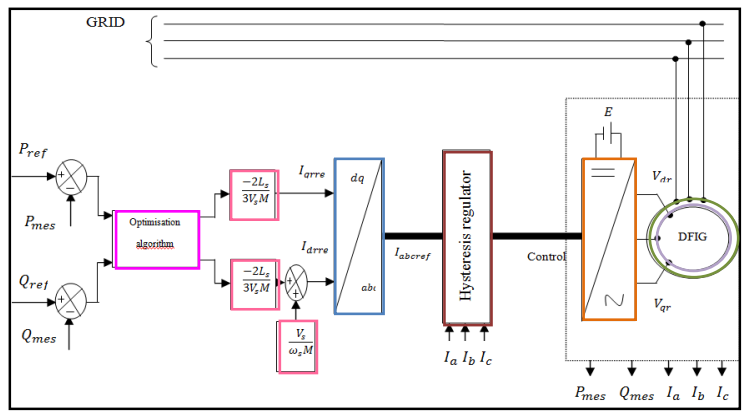

Fig. 5. Proposed predictive power control strategy applied to DFIG.

The diagram of the proposed algorithm applied to the DFIG is shown in Fig.5 . The power converter is designed to send or receive energy from the grid according of generator operation mode.

\section{SIMULATION RESUlTS}

In [15] simulation tests have been carried-out to further assess the effectiveness of the MBPC strategy. For the validation of the earlier discussed control approach in the case of irregular wave climate with time series elevation about 90s calculated from Bretschneider spectrum, simulations have been carried out by MATLAB environment. The DFIG parameters are given in the Appendix. The sampling time is $T_{e}=0.0013 \mathrm{~s}$. The elements of the matrices weights $W_{u}$ and $W_{y}$ should be adjusted carefully so that they meet the requirements desired by the designer.

It is known that the matrix $W_{u}$ is related to the control effort and its elements must be nonzero because it causes high overshoot. Already matrix $W_{y}$ emphasizes each individual prediction of the output that would improve the response time of the plant. The matrices and are given by:

$$
W_{y}=\left[\begin{array}{cc}
15 & 0 \\
0 & 45
\end{array}\right] \text { and } W_{u}=\left[\begin{array}{cc}
0.002 & 0 \\
0 & 0.01
\end{array}\right]
$$

Moreover, the adopted sampling time $T_{e}=0.00131 \mathrm{sec}$.

The power extract from the wave is adopted like an active power reference. Fig. 6. clearly shows the good power tracking performances and therefore confirms the effectiveness of the proposed model based power predictive control strategy.

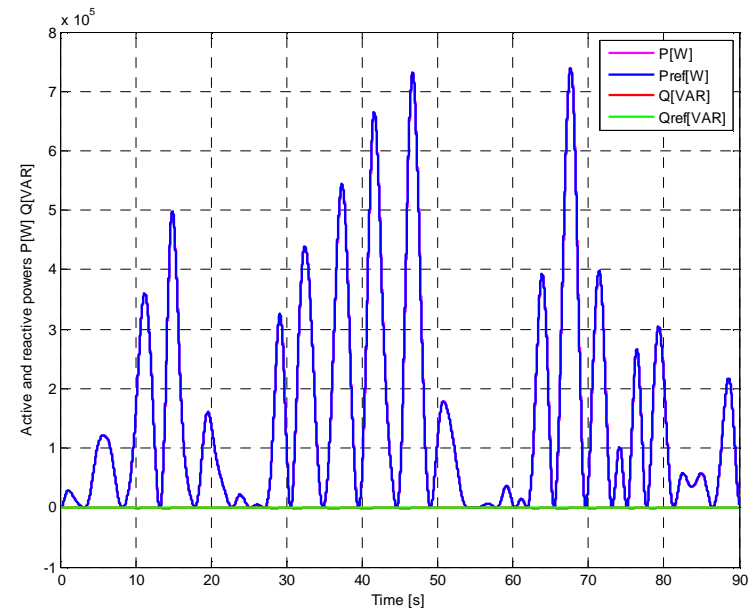

Fig. 6. Active and reactive power under irregular wave.

The fig. 7. shows DC capacitor voltage. From this value we calculate the command vector (quadrature rotor voltage) . an also voltage of semi conductor used in $\mathrm{AC} / \mathrm{AC}$ converter are controled.

In the next two figures, we present Tthe zoom of rotor currents ans we take as an exemple one phase to show that the current and the voltage are in phase that means the reactive power is zero. 


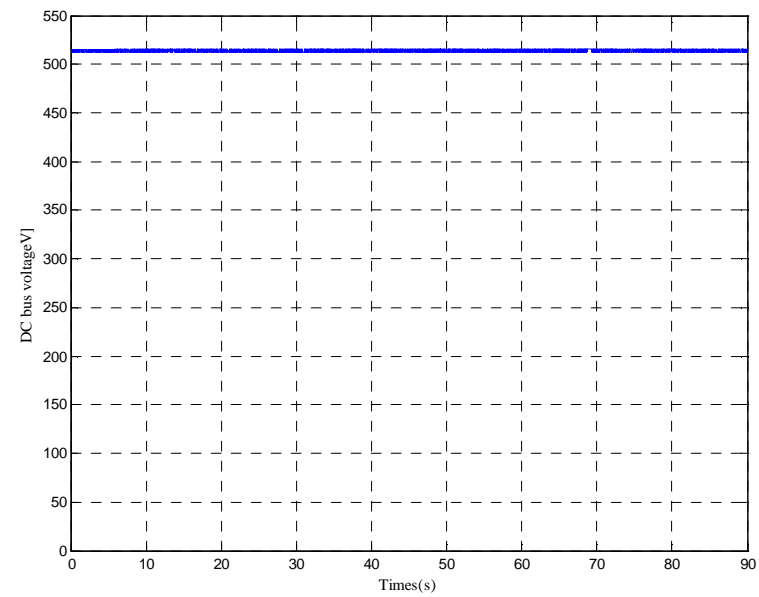

Fig. 7. capacitor voltage.

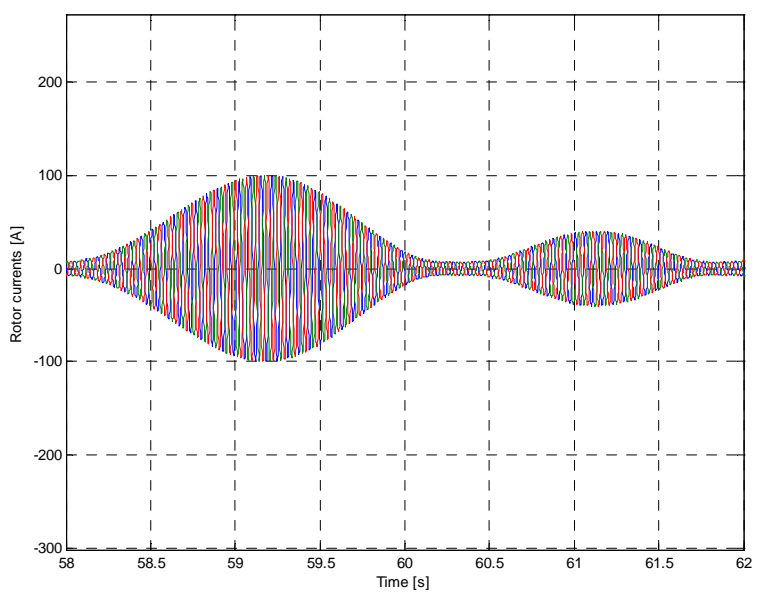

Fig. 8. Rotor currents.

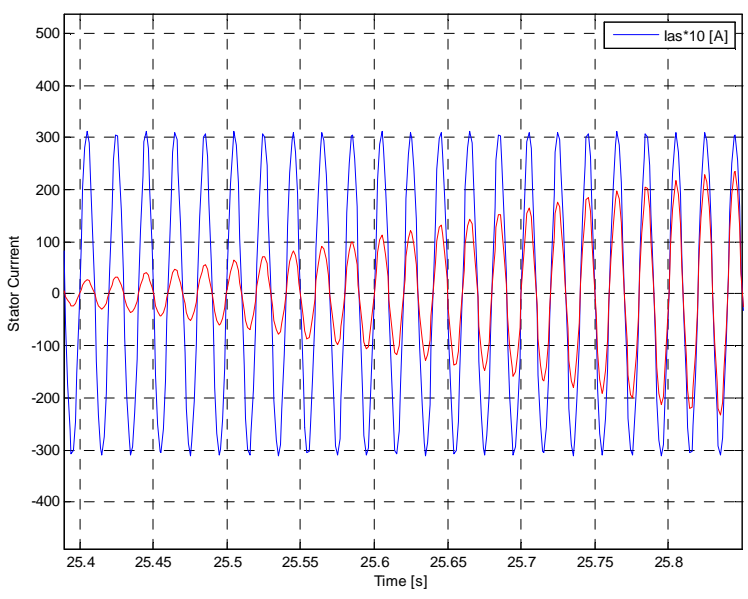

Fig. 9. Zoom in a rotor phase current and his voltage.

\section{CONCLUSION}

This paper deal with a model-based predictive power control of a doubly-fed induction generator based wave energy converter under irregular waves. These waves are modeled by using Bretschneider energy spectrum. From this spectrum we have generate times series of 90 seconds.

In this context, the control law was derived from an objective function optimization (quadratic error between the predicted powers and the specific references that are control-dependent. The predicted active/reactive powers were calculated using a linearized state-space model.

The obtained results clearly show the MBPC approach effectiveness in terms of DFIG powers tracking performances. Further investigations are required to further assess the effectiveness of the proposed MBPC under constraints (input, output and space state) for this type generator and different WECs.

\section{APPENDIX}

\section{RATED DATA OF THE SimUlated DFIG}

$$
\begin{gathered}
P n=149.2 \mathrm{Kw} ; R_{s}=0.002475 \Omega ; R_{s}=0.0133 \Omega ; \\
L_{s}=0.000284 \mathrm{H} ; L_{r}=0.000284 \mathrm{H} ; L_{r}=0.01425 \mathrm{H} \\
\mathrm{J}=2.6 \mathrm{Kg} . \mathrm{m}^{2} ; P=2 ; V n=575 \mathrm{~V}
\end{gathered}
$$

\section{REFERENCES}

[1] J. Crus Ed., Ocean Wave Energy: Current Status and Future Perspectives. Springer, Berlin, 2008.

[2] J.G. Vining A. Muetze, "Economic factors and incentives for ocean wave energy conversion," IEEE Trans. Industry Applications, vol. 45, n², pp. 547-554, March-April 2009.

[3] S. Benelghali, M.E.H. Benbouzid and J.F. Charpentier, "Marine tidal current electric power generation technology: State of the art and current status," in Proceedings of the 2007 IEEE IEMDC, Antalya (Turkey), vol. 2, pp. 1407-1412, May 2007

[4] http://www.emec.org.uk / (last accessed December 2013).

[5] M.S. Lagoun, A. Benalia and M.E.H. Benbouzid, "Ocean wave converters: State of the art and current status," in Proceedings of the 2010 IEEE ENERGYCON, Manama (Bahraïn), pp. 636-641, December 2010.

[6] B. Beltran, M.E.H. Benbouzid and T. Ahmed-Ali, "Second-order sliding mode control of a doubly fed induction generator driven wind turbine," IEEE Trans. Energy Conversion, vol. 27, n² 2, pp. 261-269, June 2012.

[7] S. Benelghali, M.E.H. Benbouzid, J.F. Charpentier, T. Ahmed-Ali and I. Munteanu, "Experimental validation of a marine current turbine simulator: Application to a PMSG-based system second-order sliding mode control," IEEE Trans. Industrial Electronics, vol. 58, ${ }^{\circ} 1$, pp.118126, January 2011.

[8] R. Pena, R. Cardenas, J. Proboste, G. Asher and J. Clare, "Sensorless control of doubly-fed induction generators using a rotor-current-based MRAS observer," IEEE Trans. Industrial Electronics, vol. 55, ${ }^{\circ} 1$, pp. 330-339, January 2008.

[9] J.W. Park, K.W. Lee and H.J. Lee, "Wide speed operation of a doublyfed induction generator for tidal current energy," in Proceedings of the 2004 IEEE IECON, Busan (South Korea), vol. 2, pp. 1333-1338, 2004.

[10] L. Xu and P. Cartwright, "Direct active and reactive power control of DFIG for wind energy generation," IEEE Trans. Energy Conversion, vol. 21, n³, pp. 750-758, September 2006.

[11] A.J. Sguarezi Filho and E.R. Filho, "Model-based predictive control applied to the doubly-fed induction generator direct power control," IEEE Trans. Sustainable Energy, vol. 3, n³, pp. 398-406, July 2012. 
[12] A.J. Sguarezi Filho, M.E. de Oliveira Filho and E. Ruppert Filho, "A predictive power control for wind energy," IEEE Trans. Sustainable Energy, vol. 2, n ${ }^{\circ}$, pp.97-105, January 2011.

[13] D. Zhi, L. Xu and B.W. Williams, "Model-based predictive direct power control of doubly fed induction generators," IEEE Trans. Power Electronics, vol. 25, n², pp. 341-351, February 2010.

[14] L. Xu, D. Zhi and B.W. Williams, "Model-based predictive direct power control of doubly fed induction generators," IEEE Trans. Industrial Electronics, vol. 56, n ${ }^{\circ} 10$, pp. 4143-4153, October 2009.

[15] M.S. Lagoun,S.Nadjem, A. Benalia and M.E.H. Benbouzid"Predictive Power Control of Doubly-Fed Induction Generator for Wave Energy Converters" Proceedings International Symposium on EnvironmentFriendly Energies and Applications pp. 312 - 317. June 2012.

[16] A. Muetze et al., "Ocean wave energy conversion - A survey," in Proceedings of the IEEE IAS'06, Tampa (USA), vol. 3, ,October 2006, pp. 1410-1417.

[17] Jan Beerens, "Offshore Hybrid Wind-Wave Energy Converter System A Frequency Domain Approach",master thesis,norwigean university,2010, pp.30.

[18] Falnes, J. (2002) Ocean waves and oscillating systems: Linear Interactions Including Wave- Energy Extraction. Cambridge University Press, iSBN 0521782112.

[19] W. Leonhard, "Control of Electrical Drives. Berlin, Germany: SpringerVerlag, 1985.

[20] Ion Boldea, "Variable speed generators", Taylor \& Francis,USA, 2006

[21] A. J. S. Filho and E. Ruppert, "A deadbeat active and reactive power control for doubly-fed induction generator," Electric Power Compon. Syst., vol. 38, no. 5, pp. 592-602, 2010. 